\title{
Effect of Stevia rebaudiana on the Bioactive Compounds from Agarwood Leaf (Aquilaria spp.) by Lactic Fermentation and Spray Drying
}

\author{
Lieu My Dong ${ }^{1 *}$, Doan Trung Nam ${ }^{1}$, Tran Thi Phuong ${ }^{1}$, and Dang Kim Thuy ${ }^{2}$ \\ ${ }^{1}$ Faculty of Food Science and Technology, Ho Chi Minh City University of Food Industry, 140 Le Trong Tan, Tay Thanh Ward, Tan Phu District, \\ Ho Chi Minh City 70000, Vietnam \\ ${ }^{2}$ Department of Plant Cell Technology, Institute of Tropical Biology, 9/621 Ha Noi highway, Ho Chi Minh City 70000, Vietnam
}

Received: January 5, 2021 / Revised: February 8, 2021 / Accepted: February 22, 2021

\begin{abstract}
Agarwood (Aquilaria spp) has high economic value. However, essential oil production from agarwood is a time-consuming process. Additionally, agarwood leaves have not been utilized even though they contain various bioactive ingredients. In this study, agarwood leaves were fermented using Lactobacillus plantarum ATCC 8014 with or without Stevia $(4,8$, and $12 \%$; v/v). The fermented fluid was mixed with maltodextrin $\left(15 \%\right.$; w/v) and subjected to spray drying (inlet temperature, $120^{\circ} \mathrm{C}$; outlet temperature, $65-70{ }^{\circ} \mathrm{C}$ ). The contents of polyphenols, polysaccharides, saponins, and flavonoids and the viability of L. plantarum were determined. Fermentation enhanced the levels of bioactive compounds. The contents of polyphenol (69.19 \pm $4.05 \mathrm{mg} \mathrm{GAE} / \mathrm{g}$ of sample), polysaccharide $(20.75 \pm 0.98 \mathrm{mg} \mathrm{GE} / \mathrm{g}$ of sample), saponin $(305.23 \pm 4.21 \mathrm{mg}$ OAE$/ \mathrm{g}$ of sample), and flavonoid (7.86 $\pm 0.72 \mathrm{mg} \mathrm{QE} / \mathrm{g}$ of sample), and the viability of L. plantarum $(8.72 \pm 0.17 \mathrm{log}$ $\mathrm{CFU} / \mathrm{ml})$ were markedly upregulated in the samples containing Stevia $(12 \%$; $/ \mathrm{v})$. This indicated that the supplementation of Stevia during fermentation decreases the fermentation time (9 h), upregulates bioactive compound production in agarwood leaves, enhances microencapsulation during spray drying, and increases the viability of $L$. plantarum under simulated gastric digestion conditions.
\end{abstract}

Keywords: Aquilaria spp, bioactive compounds, fermentation, spray drying, Stevia rebaudiana

\section{Introduction}

Agarwood plant (Aquilaria spp.) originated in Southeast Asia is known for the value of the essential oil produced in wood stems [1]. In addition to the traditional medicinal uses, it is also used in perfumes manufacture or flavoring ingredients in food products. Because of these outstanding benefits, the wood body of frankincense is the most concerning part. However, the agarwood plant usually took more than ten years for the good quality of essential oil harvest [1], so the economic issue

\section{*Corresponding author}

Tel: +84989961848

E-mail: lieudong289@gmail.com in this period should be considered. Besides the source of agarwood essential oil, previous studies have shown many bioactive compounds were found in agarwood leaves including, phenolic acids, benzophenones, xanthonoid, flavonoids, saponins, alkaloids, and steroids; ingredients showing different pharmacological effects [2, 3]. Medicinal value of agarwood leaves was proven capable antihyperglycemic [4]; antioxidants [3, 4], and antibacterial [3]. These studies suggested that using agarwood leaves would be a potential approach that not only brings economic meaning during the awaiting of essential oil but also create a new product line that brings many health benefits.

The extraction efficiency of bioactive compounds plays an important role to fully exploit these components from 
agarwood leaves. Various approaches are available such as microwave-assisted extraction, ultrasound-assisted extraction, and lactic fermentation, that improved the extraction efficiency of bioactive compounds from medicinal plants [5, 6]. Microwave-assisted extraction or ultrasonic-assisted extraction is the process of mechanically acting on the plant cell wall to disrupt and improve extraction efficiency [5]. However, this mechanical process often causes overheating during the treatment leading to the effect of bioactive compounds [7]. Unlike microwave or ultrasonic extraction, fermentation is conducted at a constant temperature and does not cause overheating during the fermentation process. Also, fermentation could promote the metabolism of biological substances that alter product properties for higher value [8]. Among other fermentation processes, lactic fermentation is being widely used in which Lactobacillus plantarum is most frequently used in the fermentation of plant-based food products [9]. In addition, fermentation caused destruction and alterations that increase the bioactive substances [9]. During growing, probiotic strains will convert sugars into lactic acid and create antibacterial compounds such as hydrogen peroxide, bacteriocins, reducing the $\mathrm{pH}$ of the product facilitates the inhibition of harmful microorganisms [10]. However, agarwood leaf is not a familiar substrate source for probiotic bacteria that could delay the extraction of bioactive compounds. Besides, agarwood leaves contain high tannins and saponins contents, resulting in an acrid and strong bitter taste [2]. Therefore, providing the substrate source for probiotic bacteria as well as reducing the sensory effect of the fermentation extract should be considered in which the use of stevia (Stevia rebaudiana) could achieve these values. Stevia is 300 times sweeter than sucrose and does not affect blood glucose levels thanks to the active ingredient steviol in its composition [11]. Stevia has been approved by the Food and Drug Administration for safety and is widely used in the food industry as a sugar substitute [11]. Besides, the ingredients in stevia have been shown to stimulate the growth of probiotic bacteria $[12,13]$.

For extracting fluid from the herb, the preservation and maintenance of the bioactive compounds are very important. The making of powder products by spray drying method is commonly used because it offers many advantages such as; ease of use, prolonged storage time
$[14,15]$. Also, this method was proven effective in the packaging of food ingredients sensitive to heat as polyphenols, anthocyanins, $\beta$-carotene, and carotenoids, as well as protect microorganisms under the effect of hightemperature spray drying because the carrier acts as a coating material $[16,17]$. Although many studies on the extraction of biological compounds from medicinal plants using fermentation processes, studies on agarwood leave supplemented with stevia and evaluated the ability to maintain these compounds as well as the viability of probiotic bacteria was poorly reported. Therefore, this study evaluated the effect of fermentation, rate supplement stevia, and spray drying process on the extraction efficiency of bioactive compounds from agarwood leaves. The evaluation criteria are the total polyphenols, total polysaccharides, total saponins, total flavonoid contents, and $L$. plantarum viability. The $L$. plantarum survival in SGF (Simulated gastric fluid) and SIF (Simulated intestinal fluid) after spray drying process was also evaluated in this study.

\section{Materials and Methods}

\section{Materials}

Aquilaria spp leaves (Fig. 1) from Dong Nai province, which is located at $10^{\circ} 51^{\prime} 20.0^{\prime \prime} \mathrm{N} 106^{\circ} 57^{\prime} 28.3 \mathrm{E}$ in the Southeast region of Vietnam. Aquilaria spp leaves (5-6 years old) were selected in the same color and size, washed, and dried with absorbent paper. The leaves were then milled by a blender (HR2118/01, Netherlands). $100 \mathrm{ml}$ of water was added to $4 \pm 0.01$ grams of sample, the mixture used for the fermentation process.

Stevia (Stevia rebaudiana) after collecting samples in Hung Yen province, which is located at $20^{\circ} 39^{\prime} \mathrm{N} 106^{\circ} 04^{\prime} \mathrm{E}$

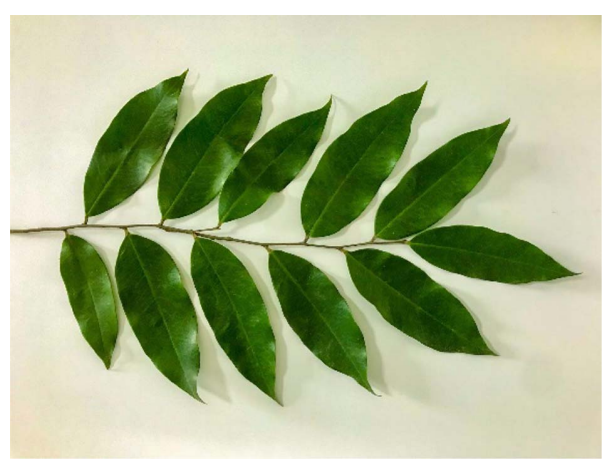

Fig. 1. Aquilaria spp. leaves. 
in the northern part of Vietnam. Stevia was dried and crushed by the blender. $140 \mathrm{ml}$ of water added to $4 \pm 0.01$ grams of fresh grass soaked in a water bath (WNE 22, Germany) at $65^{\circ} \mathrm{C}, 3 \mathrm{~h}$. Obtain the extract and add it to the fermentation process.

Lactobacillus plantarum ATCC 8014 strain was obtained from the strain collection of the Faculty of Food Science and Technology, the Ho Chi Minh City University of Food Industry. The strain was incubated on Man Rogosa Sharpe (MRS) medium at $37^{\circ} \mathrm{C}$ in $24 \mathrm{~h}$. Biomass was collected by centrifuge (Z206A, Hermle, Germany) and suspended in $10 \mathrm{ml}$ of saline water $(0.9 \% \mathrm{w} / \mathrm{v})$ for the fermentation process.

\section{Fermentation process}

The milled agarwood was fermented by $L$. plantarum (7 $\log \mathrm{CFU} / \mathrm{ml}$ ) with or without the addition of stevia (4; 8 ; and $12 \% \mathrm{v} / \mathrm{v}$ ) at $37^{\circ} \mathrm{C}$. Samples were examined for bioactive compounds and L. plantarum density every $3 \mathrm{~h}$ during $36 \mathrm{~h}$ of fermentation. The density of $L$. plantarum was determined on the MRS medium after $48 \mathrm{~h}$ of incubation at $37^{\circ} \mathrm{C}$.

\section{Spray drying process}

Agarwood extract mixture after fermentation was supplemented with maltodextrin (PCT0611, India) 15\% (w/v) and spray-dried with parameters: $4.5 \mathrm{ml} / \mathrm{min}$, injector diameter $0.5 \mathrm{~mm}$, the pressure was $2 \mathrm{~atm}$, the inlet temperature was $120^{\circ} \mathrm{C}$, the outlet temperature was 65-70 ${ }^{\circ}$. The bioactive compounds content and the $L$. plantarum viability were checked before and after the spray drying process through microencapsulation efficiency to evaluate the effect of the drying process. Microencapsulation efficiency (ME) was calculated based on the following formula:

$$
\begin{aligned}
& \operatorname{ME}(\%)=\frac{\begin{array}{c}
\sum \text { bioactive compounds content or density } \\
\text { of } L \text { plantarum after drying }
\end{array}}{\sum \text { bioactive compounds content or density }} \times 100 \% \\
& \text { of } L \text {. plantarum before drying }
\end{aligned}
$$

\section{Analytical method}

Determination of total phenolic content. Total phenolic content was conducted as described by Vuong et al. (2013) with some changes [18]. $1 \mathrm{ml}$ of the diluted sample 10 times into a test tube, then add $5 \mathrm{ml}$ of Folin-
Ciocalteu reagent, mix, allow $5 \mathrm{~min}$ to occur, then $4 \mathrm{ml}$ of $7.5 \%$ sodium carbonate (w/v), let stand in the dark for $1 \mathrm{~h}$. The absorbance was measured with a wavelength of $765 \mathrm{~nm}$. Results are expressed in mg gallic acid equivalent per gram of sample (mg GAE/g sample) based on the gallic acid calibration curve.

Determination of total polysaccharide content. Total polysaccharide content was conducted according to the description of Ly et al. (2019) with some changes [19]. $1 \mathrm{ml}$ of sample, add $5 \mathrm{ml}$ of ethanol $96{ }^{\circ} \mathrm{C}$, hold at $4{ }^{\circ} \mathrm{C}$ for $24 \mathrm{~h}$. Centrifuge the precipitate, dissolve the precipitate, and add to $10 \mathrm{ml}$ with hot water at $70^{\circ} \mathrm{C}$. Aspirate $2 \mathrm{ml}$ of the above diluent into a test tube and add $8 \mathrm{ml}$ of the anthrone reagent in concentrated sulfuric acid medium. Allow to stand at room temperature for $30 \mathrm{~min}$ and measure the absorbance at $630 \mathrm{~nm}$. The results were calculated by $\mathrm{mg}$ D-glucose equivalent per gram of sample (mg GE/g sample) which was based on the calibration curve of $\mathrm{D}$-glucose.

Determination of total flavonoid content. Total flavonoid content was described by Zhishen et al. (1999) with some changes [20]. $1 \mathrm{ml}$ of the sample into a $10 \mathrm{ml}$ volumetric flask containing $4 \mathrm{ml}$ of distilled water twice. Then add $0.3 \mathrm{ml}$ of $5 \%$ sodium nitrite (w/v) and shake well. After $5 \mathrm{~min}$, add $0.3 \mathrm{ml}$ of $10 \%$ aluminum chloride (w/v), continue for $5 \mathrm{~min}$, add $2 \mathrm{ml}$ of $1 \mathrm{M}$ sodium hydroxide, and add to volume with distilled water twice. Allow to stand at room temperature for $10 \mathrm{~min}$ and measure the absorbance at $510 \mathrm{~nm}$. Results were expressed in mg quercetin equivalent per gram of sample (mg QE/g sample) based on the quercetin calibration curve.

Determination of total saponin content. Total saponin content was performed as described by Chen et al. (2007) with some changes [21]. $0.2 \mathrm{ml}$ of the diluted sample 5 times into a test tube. Vanillin-acetic acid $0.2 \mathrm{ml}, 5 \%$ (w/v), and $1.2 \mathrm{ml}$ of perchloric acid were added, mixed well, and placed in a water bath at $70^{\circ} \mathrm{C}$ for $20 \mathrm{~min}$. The mixture was cooled rapidly for $2 \mathrm{~min}$ and made up to $5 \mathrm{ml}$ with ethyl acetate. The absorbance is measured at $550 \mathrm{~nm}$. Results were calculated using mg oleanolic acid equivalent per gram of sample (mg OAE/g sample) which was based on the calibration curve of oleanolic acid. 
Test for the viability of $L$. plantarum in SGF and SIF. The experiment was carried out as described by Gbassi et al. (2009) [22]. Simulated gastric fluid (SGF) consisting of $9 \mathrm{~g} / \mathrm{l} \mathrm{NaCl}+3 \mathrm{~g} / \mathrm{l}$ pepsin adjusted $\mathrm{pH}$ to 2.5 with $5 \mathrm{M} \mathrm{HCl}$ and Simulated intestinal fluid (SIF) consisting of $9 \mathrm{~g} / \mathrm{l}$ $\mathrm{NaCl}+3 \mathrm{ml} / \mathrm{l}$ beef bile adjusted $\mathrm{pH}$ to 6.5 with $5 \mathrm{M}$ $\mathrm{NaOH}$.

The $4 \mathrm{~g}$ sample was incubated in $36 \mathrm{ml}$ of SGF medium for $2 \mathrm{~h}$ at $37^{\circ} \mathrm{C}$, the sample was then transferred to SIF medium and incubated for $4 \mathrm{~h}$ at $37^{\circ} \mathrm{C}$. The viability of $L$. plantarum was assessed on the MRS medium after $48 \mathrm{~h}$ of incubation at $37^{\circ} \mathrm{C}$.

Statistical analysis. All experiments were repeated three times, results presented as mean \pm standard deviation. Results were calculated using Microsoft Office Excel 2019 software and SPSS 20.0 statistical software. ANOVA analysis results with $95 \%$ confidence, comparing the differences between the treatments through the Tukey and Duncan test.

\section{Results and Discussion}

\section{Effect of the fermentation process and mixing ratio of ste- via on bioactive compounds from agarwood leaves}

The effect of the lactic fermentation process with or without stevia supplement on the ability to extract bioactive compounds was shown in Figs. 2, 3. In the sample without adding stevia, the content of polyphenol, saponin, and polysaccharide increased significantly ( $p<$ 0.05 ) after $12 \mathrm{~h}$ of fermentation compared to initial time with the corresponding content $53.65 \pm 1.38 \mathrm{mg}$ GAE $/ \mathrm{g}$ sample; $211.9 \pm 3.15 \mathrm{mg} \mathrm{OAE} / \mathrm{g}$ sample; and $16.97 \pm 0.97$ mg GE/g sample (Figs. 2 and 3). The stevia supplement samples at a concentration of $4 \%(\mathrm{v} / \mathrm{v})$, was shown a similar trend of increase. However, when the stevia concentration increased to $8 \%$ and $12 \%(\mathrm{v} / \mathrm{v})$, the bioactive ingredients from agarwood leaves achieved the highest value after $9 \mathrm{~h}$ of fermentation, and $12 \%(\mathrm{v} / \mathrm{v})$ of the stevia reached the highest level in terms of the total content of polyphenols, polysaccharides, saponins with $69.19 \pm 4.05 \mathrm{mg}$ GAE/g sample; $20.75 \pm 0.98 \mathrm{mg} \mathrm{GE} / \mathrm{g}$ sample; and $305.23 \pm 4.21 \mathrm{mg} \mathrm{OAE} / \mathrm{g}$ sample, respectively (Figs. 2 and 3).

The results show that $L$. plantarum the extraction and metabolism of bioactive compounds from agarwood

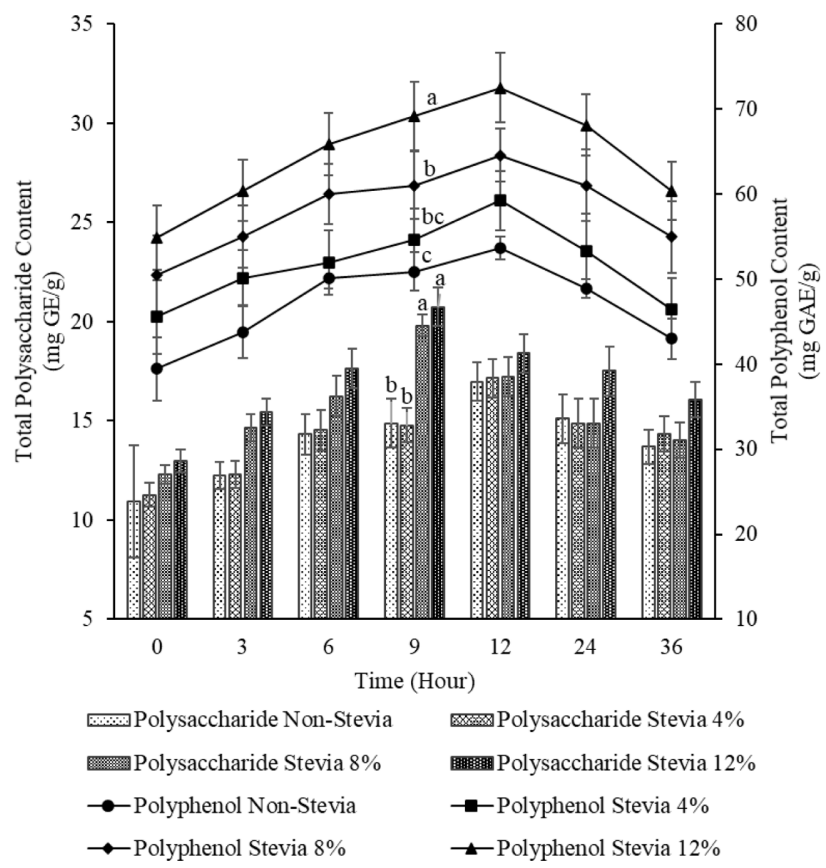

Fig. 2. Effects of fermentation and mixing ratio of stevia on the total content of polysaccharide and polyphenol. ${ }^{a b c}$ the mean values between the four samples, the character differences have statistically significant differences $(p<0.05)$.

leaves. The positive effects of lactic fermentation on the extraction of biologically active substances from plants have been reported in previous studies. Research by Septembre et al. (2018) reported the improvement of phenolic compounds through polymer hydrolysis due to lactic fermentation on fresh fruits and vegetables [9]. Similarly, Limón et al. (2015) indicated that lactic fermentation by L. plantarum increased the phenolic compounds content in kidney beans [6]. These results would be due to lactic bacteria possessing significant enzymes during extraction such as amylase, $\beta$-glucosidase, decarboxylase, peptidases, phenolic acid decarboxylases, proteinase, tannase [23]. These enzymes cause structural disruption of the plant cell wall, leading to the release or synthesis of various compounds [23]. However, the bioactive compounds tended to decline with prolonged fermentation time (Figs. 2 and 3). During the fermentation process, the lactic bacteria produce organic acids that decrease $\mathrm{pH}$ over fermentation time. Sestelo et al. (2004) suggested that among produced enzymes, $\beta$ glucosidase begin to be inactivated when the $\mathrm{pH}$ drops below 4 [24]. Besides, the presence of lactic bacteria contributes to simple phenolic conversion and reduction of 


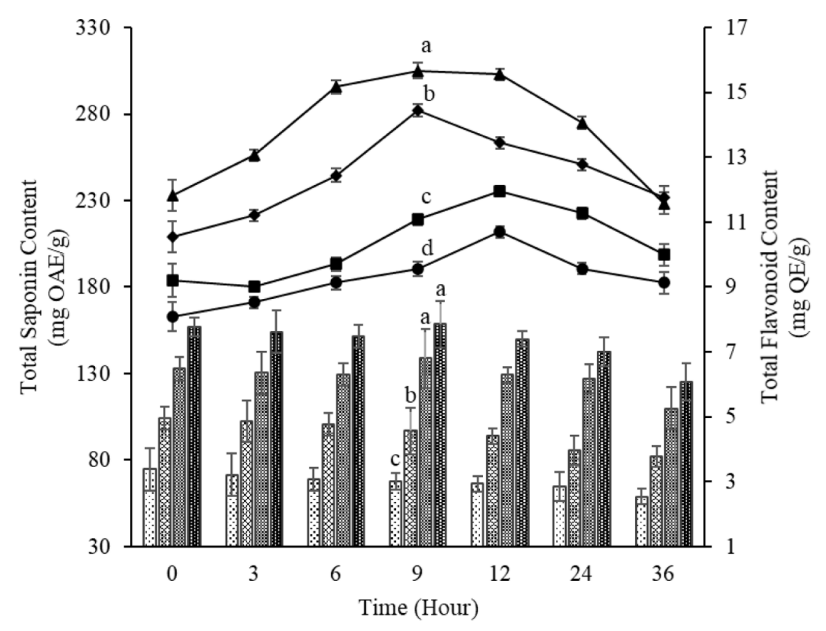

Flavonoid Non-Stevia

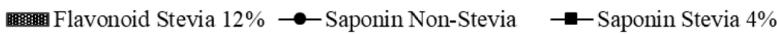

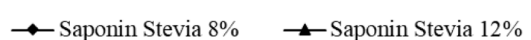

Fig. 3. Effects of fermentation and mixing ratio of stevia on the total content of saponin and flavonoid. ${ }^{a b c}$ the mean values between four samples, the character differences have statistically significant differences $(p<0.05)$.

phenolic compounds with high molecular weight, so the polyphenol content was reduced during long-term fermentation [19]. However, the flavonoid content did not find a similar trend in both samples that content with or without stevia. Flavonoid content decreased from the early stages of fermentation though a significant difference compared to initial time was not recorded $(p>0.05)$ (Fig. 3). Limón et al. (2015) also observed a decrease in flavonoid content after kidney bean fermentation with $L$. plantarum ATCC 14917 strain [6]. Lee et al. (2018) indicated that the total flavonoid content in soybeans was not significantly affected by the fermentation process and genetics of $L$. plantarum P1201 strain leading to there was no increase in content like polyphenol content [25].

The study results also indicated that the L. plantarum viability increased significantly during the fermentation process compared to initial time (Fig. 4). This showed that the extracted fluid of agarwood leaf could provide the necessary substrate source for the L. plantarum growth. The results also indicated that there was no significant difference between the samples with or without stevia at a concentration of $4 \%(\mathrm{v} / \mathrm{v})$. However, by increasing stevia concentration of $8 \%$ to $12 \%(\mathrm{v} / \mathrm{v})$, the viable $L$. plantarum was improved as well as reducing the fer-

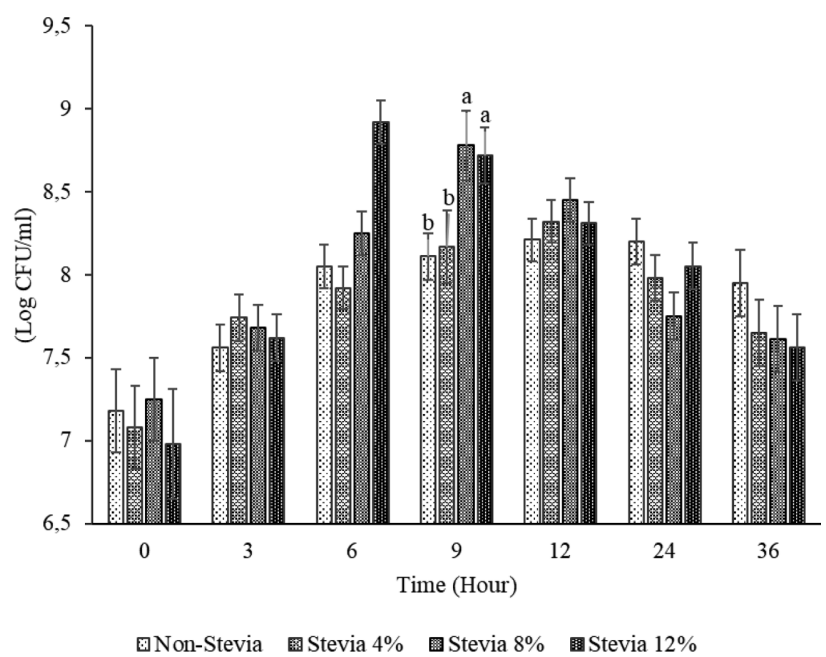

Fig. 4. Effects of fermentation and mixing ratio of stevia on L. plantarum viability. ${ }^{a b c}$ the mean values between four samples, the character differences have statistically significant differences $(p<0.05)$.

mentation time which required $9 \mathrm{~h}$ to reach the best results compared to $12 \mathrm{~h}$ in the samples without stevia (Figs. 2 and 3). Also, the bioactive compounds significantly higher than the samples without stevia.

Improving the extraction efficiency of bioactive compounds as well as increase the probiotic viability after the fermentation process plays an important role. The results also showed that the density of $L$. plantarum has relative to the content of bioactive substances from agarwood leaves. The increase in L. plantarum density increased the extraction efficiency of bioactive compounds in which the addition of stevia ( $8 \%$ and $12 \% \mathrm{v} / \mathrm{v})$ increased L. plantarum viability and reduced the required time to acquire the bioactive compounds (Figs. 2, 3, and 4). Previous studies have shown that stevia contains fructo-oligosaccharides (FOS), a prebiotic form that could stimulate lactic bacteria growth [12]. Besides, the main sweetener component of stevia is steviol glucoside has also been shown to be a sugar substitute for probiotic fermentation, that significantly improved the L. acidophilus growth [13]. These showed that the addition of stevia to the lactic fermentation process of agarwood leaves could improve benefit bacteria, increases the efficient extraction of bioactive substances, and enhances sensory value to post-fermentation products. Increasing stevia concentration (up to $16 \% \mathrm{v} / \mathrm{v}$ ) was not improved ( $p>0.05$ ) the sensory value, the content of the bioactive compounds, and 
the viable $L$. plantarum compared to the lower concentration $(12 \% \mathrm{v} / \mathrm{v})$ (data not shown). The results obtained from the study showed that the supplementation of $8 \%$ and $12 \%$ stevia was necessary to shorten the fermentation time while ensuring the highest concentration of probiotic bacteria (Figs. 2-4).

\section{Effect of spray-drying on bioactive compounds and $L$. plantarum viability}

The effect of spray drying on bioactive compounds and the L. plantarum viability was shown in Fig. 5. The results showed that the microencapsulation efficiency in the sample without adding stevia was $47.49 \%$; $62.44 \%$; $47.22 \%$; $66.92 \%$; and $84.82 \%$, corresponding to the total content of polyphenol; polysaccharide; saponin; flavonoid; and L. plantarum survival rate, respectively (Fig. 5). The samples contain stevia showed improve microencapsulation efficiency of bioactive compounds and the probiotic bacteria survival after the spray-drying process. The stevia concentration of $8 \%$ and $12 \%(\mathrm{v} / \mathrm{v})$ reached the microencapsulation efficiency of the total of polyphenol, polysaccharide, saponin, flavonoid, and $L$. plantarum viability was $51.2 \%$ and $53.55 \%$; $61.55 \%$ and $63.64 \%$; $54.55 \%$ and $64.64 \%$; $68.13 \%$ and $69.63 \%$; and $88.61 \%$ and $92.45 \%$ respectively.

The spray drying process creates a powder product,

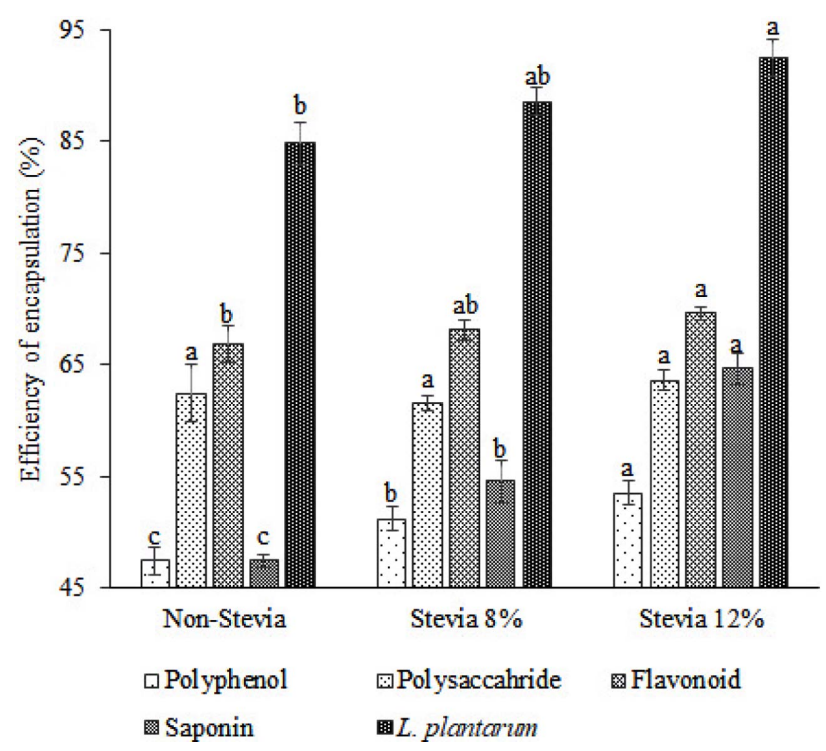

Fig. 5. Effect of spray drying on bioactive compounds and L. plantarum viability. ${ }^{a b c}$ the mean values between the three samples, the character differences have statistically significant differences $(p<0.05)$. making it easy to use and prolonging product storage time. However, for bioactive substances and probiotics, high temperatures in the spray-drying process should concern. Tchabo et al. (2019) indicated that an increase in inlet temperature of 120 to $160^{\circ} \mathrm{C}$ decreased the total content of polyphenols, flavonoids, and other bioactive compounds [26]. Besides, increase the temperature would be destroyed saponins, which are heat-sensitive [27]. The recovery rate of polyphenols decreased $73 \%$ when the spray-drying temperature was $140{ }^{\circ} \mathrm{C}$ [28] and the survival rate of the probiotic decreased to $80 \%$ when the inlet temperature was $155^{\circ} \mathrm{C}$ [29] whereas, the remaining the total content of polyphenol and flavonoid was up to $62 \%$ and $73 \%$ respectively when the spray drying temperature was $100^{\circ} \mathrm{C}$ [30]. However, the spray drying temperature below $120^{\circ} \mathrm{C}$ results in low powder yield and high powder moisture [26]. In the present study, the spray-drying process with an inlet temperature of $120^{\circ} \mathrm{C}$ showed a significant impact on the bioactive compounds in agarwood leaves as well as L. plantarum survival (Fig. 5). An increase in the inlet temperature caused a more decrease in the bioactive compounds and L. plantarum survival, whereas a decrease in inlet temperature caused high powder moisture (data not shown). These results indicated that the inlet temperature affected bioactive compounds and probiotic viability during the spray drying process. Therefore, the choice of wall materials is necessary to improve the microencapsulation efficiency.

Maltodextrin is a commonly used carrier in spray drying because of its properties as a prebiotic that protects probiotic bacteria, improves the recovery efficiency of bioactive compounds, is cheap, and prevents adhesion to the wall of equipment when spray drying [15, 16]. However, to further improve the protective effect of the wall materials, adjuvant compounds are often used. Research by Çam et al. (2018) showed that maltodextrin combined with gum arabic at different proportions (0$100 \%$ ) did not show the difference in polyphenol content, but was effective in storing essential oils and increasing the sensory value of soluble mint tea [31]. Mahdi et al. (2019) showed that combinations of different carriers gave different polyphenol microencapsulation efficiencies, $87.20 \%$ for spray-drying with a mixture of maltodextrin, gum arabic, and modified starch and $72.11 \%$ for with a mixture of maltodextrin, modified starch, and whey pro- 
tein [32]. Maltodextrin in combination with whey protein improved the Lactobacillus rhamnosus viability, and the L. rhamnosus viability was more increased significant by partial replacement of maltodextrin to sucrose or trehalose [14]. Besides, the previous studies also indicated that prebiotics act as an effective supporting ingredient for the spray drying process. Research by Kalita et al. (2018) indicated that the combination of maltodextrin and FOS improved the L. plantarum viability after the spray drying process [33]. Similarly, the study of Sosa et al. (2016) showed that the survival of $L$. plantarum strain was $93 \%$ when combining maltodextrin and galacto-oligosaccharides, whereas only $64 \%$ of cells survived spray drying with maltodextrin [34]. These results suggested that the combination of maltodextrin with other carrier ingredients is necessary to improve the efficiency of the drying process. The results obtained from the study showed that the addition of stevia $(8 \%$ and $12 \% \mathrm{v} / \mathrm{v})$ significantly improved the spraydrying performance in which the content of bioactive substances, as well as the survival rate of bacteria probiotics, were significantly improved compared to controls containing only maltodextrin (Fig. 5). The role of stevia in the spray-drying process is not well understood. The stevia composition contains fructo-oligosaccharides (FOS), which acts as a prebiotic [12]. Therefore, the positive impact of stevia on bioactive compounds of agarwood leaves and L. plantarum survival during the spray drying process could be related to prebiotic ingredients in stevia.

\section{Survival of L. plantarum ATCC 8014 strain in simulated gastric digestion after spray drying process}

The viability of L. plantarum under SGF and SIF condition was presented in Fig. 6 . The survival rate of $L$. plantarum was significantly affected $(p<0.05)$ by simulated gastric digestion conditions. In the case of the fermented sample without the addition of stevia, the survival rate of L. plantarum was $50.67 \%$ and $31.67 \%$ after $2 \mathrm{~h}$ incubation in SGF and the next $4 \mathrm{~h}$ of incubation in SIF (Fig. 6). In the case of fermented samples containing stevia, the survival rate of L. plantarum was significantly improved compared to the non-stevia samples. The survival rate of L. plantarum in the samples containing stevia $8 \%(\mathrm{v} / \mathrm{v})$ and $12 \%(\mathrm{v} / \mathrm{v})$ was $59 \%$ and $65 \%$ after $2 \mathrm{~h}$ of incubation in SGF condition and the

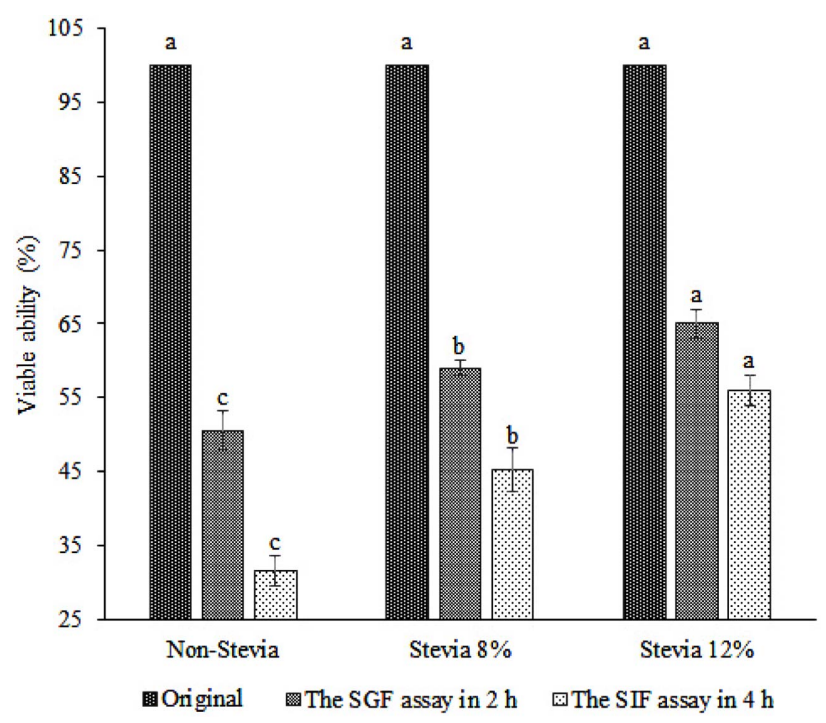

Fig. 6. Survival of $L$. plantarum strains under SGF and SIF conditions. ${ }^{a b c}$ the mean values between the three samples, the character differences have statistically significant differences $(p<0.05)$.

next $4 \mathrm{~h}$ incubation in SIF condition was $45.33 \%$ and $56 \%$ (Fig. 6).

The viability of probiotic bacteria in gastrointestinal conditions plays an important role, determining the health benefits that this strain brings. In the SGF condition, low $\mathrm{pH}$ inhibits microbial growth and reduces viable probiotic bacteria [35]. Depending on the strain, the ability to survive under these conditions varies. Previous studies indicated that free-form probiotic bacteria exhibited poor viability in gastrointestinal conditions. In the study of Ding et al. (2007), L. plantarum strain decreased by more than $6 \log \mathrm{CFU} / \mathrm{ml}$ from $10.59 \pm 0.41 \log \mathrm{CFU} /$ $\mathrm{ml}$ to $3.98 \pm 0.29 \log \mathrm{CFU} / \mathrm{ml}$ after $2 \mathrm{~h}$ of incubation at pH 2 and L. acidophilus also decreased by 6 log CFU/ml under the same conditions [36]. Therefore, microencapsulating these strains is necessary. The use of modified starch or inulin as a coating material formed during spray-drying for probiotic microencapsulation has been tested [29]. These coating materials would potentially increase the viability of probiotic bacteria under simulated gastrointestinal conditions [29, 33]. Additionally, the prebiotic role that enhances probiotic viability has also been proved in previous studies [33]. Maltodextrin has been shown to play a prebiotic role, helping to improve the viability of probiotic bacteria [16, 33]. This provides improved the viability of $L$. plantarum in SGF 
and SIF conditions (Fig. 6). Besides, stevia containing FOS ingredients acts as a prebiotic source that helps to increase the survival rate in simulated digestive conditions in fermented juice [12, 37]. Therefore, the combination of maltodextrin and stevia, which all containing prebiotic sources could make a double effect that improved the L. plantarum viability (Fig. 6). The results showed that supplementing with stevia $(12 \% \mathrm{v} / \mathrm{v})$ was the most effective for the survival of L. plantarum under SGF and SIF (Fig. 6). The L. plantarum viability was not significantly different increasing the stevia concentration to $16 \%(\mathrm{v} / \mathrm{v})$ as well as the sensory was lower than that at stevia concentrations $12 \%(\mathrm{v} / \mathrm{v})$ (data not shown). This suggested that supplement stevia was not only to reduce the fermentation time require but also to improve the bioactive compounds from agarwood leaves and the $L$. plantarum viability in simulated gastric digestion.

\section{Conclusion}

The results showed that $L$. plantarum could grow well in agarwood leaves fluid. The content of bioactive compounds such as the total content of polyphenols, polysaccharides, saponins, and flavonoids achieved the best value after $9 \mathrm{~h}$ of fermentation. The spray drying process affected the bioactive compounds from agarwood leaves significantly. The study indicated that the addition of stevia in the fermentation process has many meaningful roles; firstly, it helps to reduce the fermentation time require ( $9 \mathrm{~h}$ of fermentation), improve the extracting efficiency of bioactive compounds from agarwood leaves; second, enhancing microencapsulation efficiency in the spray drying process, and ultimately helping to improve the $L$. plantarum viability under simulated gastric digestion. The study showed the potential application of fermented agarwood leaf as a health benefit product besides agarwood essential oil source.

\section{Conflict of Interest}

The authors have no financial conflicts of interest to declare.

\section{References}

1. Kalita P, Roy PK, Sen S. 2020. Agarwood: Medicinal side of the fragrant plant. In Herbal Medicine in India, pp. 223-236. Springer, Singapore.
2. Batubara R, Hanum TI, Surjanto. 2018. Phytochemical and tannin content in two species of agarwood leaves from Mandailing Natal Regency North Sumatera Province. In AIP Conference Proceedings, Vol. 2049, No. 1, pp. 030009. AIP Publishing LLC.

3. Kamonwannasit S, Nantapong N, Kumkrai P, Luecha P, Kupittayanant S, Chudapongse N. 2013. Antibacterial activity of Aquilaria crassna leaf extract against Staphylococcus epidermidis by disruption of cell wall. Annal. Clin. Microbiol. Antimicrob. 12: 20.

4. Manoka S, Sungthong B, Sato H, Sugiyama E, Sato VH. 2016. Hypoglycemic and antioxidant activities of the water extract of aquilaria crassna leaves in streptozotocin-nicotinamide-induced Type-2 diabetic mice. Nat. Prod. Commun. 11: 757-761.

5. Pang SF, Lau MZ, Yusoff MM, Gimbun J. 2017. Microwave-irradiation induced fast simultaneous extraction of methoxylated and hydroxylated phenolic compounds from orthosiphon stamineus leaves. In Materials Science Forum, Vol. 890, pp. 155-158. Trans Tech Publications Ltd., Switzerland.

6. Limón Rl, Peñas E, Torino MI, Martínez-Villaluenga C, Dueñas M, et al. 2015. Fermentation enhances the content of bioactive compounds in kidney bean extracts. Food Chem. 172: 343-352.

7. Yeong YL, Pang SF, Chong SY, Gimbun J. 2018. Comparison of microwave and ultrasonic assisted extraction of kaempferol from Cassia alata. Int. J. Eng Technol. 7: 84-89.

8. Hussain A, Bose S, Wang JH, Yadav MK, Mahajan GB, Kim H. 2016. Fermentation, a feasible strategy for enhancing bioactivity of herbal medicines. Food Res. Int. 81: 1-16.

9. Septembre-Malaterre A, Remize F, Poucheret P. 2018. Fruits and vegetables, as a source of nutritional compounds and phytochemicals: Changes in bioactive compounds during lactic fermentation. Food Res. Int. 104: 86-99.

10. Parvez S, Malik KA, Ah Kang S, Kim HY. 2006. Probiotics and their fermented food products are beneficial for health. J. Appl. Microbiol. 100: 1171-1185.

11. Perrier JD, Mihalov JJ, Carlson SJ. 2018. FDA regulatory approach to steviol glycosides. Food Chem. Toxicol. 122: 132-142.

12. Lopes SMS, Francisco MG, Higashi B, de Almeida RTR, Krausová G, Pilau EJ, et al. 2016. Chemical characterization and prebiotic activity of fructo-oligosaccharides from Stevia rebaudiana (Bertoni) roots and in vitro adventitious root cultures. Carbohydr. Polym. 152: 718-725.

13. Ozdemir T, Ozcan T. 2020. Effect of steviol glycosides as sugar substitute on the probiotic fermentation in milk gels enriched with red beetroot (Beta vulgaris L.) bioactive compounds. LWT 134: 109851.

14. Agudelo J, Cano A, González-Martínez C, Chiralt A. 2017. Disaccharide incorporation to improve survival during storage of spray dried Lactobacillus rhamnosus in whey protein-maltodextrin carriers. J. Funct. Foods 37: 416-423.

15. de Souza MM, Santos AM, Converti A, Maciel MIS. 2020. Optimisation of umbu juice spray drying, and physicochemical, microbiological and sensory evaluation of atomised powder. J. Microencapsul. 37: 230-241.

16. Yeo SK, Liong MT. 2010. Effect of prebiotics on viability and 
growth characteristics of probiotics in soymilk. J. Sci. Food Agric. 90: 267-275.

17. Corrêa-Filho LC, Lourenço MM, Moldão-Martins M, Alves VD. 2019. Microencapsulation of $\beta$-Carotene by spray drying: effect of wall material concentration and drying inlet temperature. Int. J. Food Sci. 2019: 8914852.

18. Vuong QV, Hirun S, Roach PD, Bowyer MC, Phillips PA, Scarlett CJ. 2013. Effect of extraction conditions on total phenolic compounds and antioxidant activities of Carica papaya leaf aqueous extracts. J. Herb. Med. 3: 104-111.

19. Ly NT, Tham NT, Thuy DTK, Dong LM. 2019. Extraction of bioactive component from herbal Anoectochilus formosanus hayata by microwave, ultrasound and lactic fermentation. Turkish J. Agric. Food Sci. Technol. 7: 593-597.

20. Zhishen J, Mengcheng T, Jianming W. 1999. The determination of flavonoid contents in mulberry and their scavenging effects on superoxide radicals. Food Chem. 64: 555-559.

21. Chen Y, Xie MY, Gong XF. 2007. Microwave-assisted extraction used for the isolation of total triterpenoid saponins from Ganoderma atrum. J. Food Eng. 81: 162-170.

22. Gbassi G, Vandamme T, Ennahar S, Marchioni E. 2009. Microencapsulation of Lactobacillus plantarum spp. in an alginate matrix coated with whey proteins. Int. J. Food Microbiol. 129: 103-105.

23. Hur SJ, Lee SY, Kim YC, Choi I, Kim GB. 2014. Effect of fermentation on the antioxidant activity in plant-based foods. Food Chem. 160: 346-356.

24. Sestelo ABF, Poza M, Villa TG. 2004. $\beta$-Glucosidase activity in a Lactobacillus plantarum wine strain. World J. Microbiol. Biotechnol. 20: 633 .

25. Lee JH, Kim B, Hwang CE, Haque MA, Kim SC, Lee CS, et al. 2018. Changes in conjugated linoleic acid and isoflavone contents from fermented soymilks using Lactobacillus plantarum P1201 and screening for their digestive enzyme inhibition and antioxidant properties. J. Funct. Foods 43: 17-28.

26. Tchabo W, Ma Y, Kaptso GK, Kwaw E, Cheno RW, Xiao L, et al. 2019. Process analysis of mulberry (Morus alba) leaf extract encapsulation: Effects of spray drying conditions on bioactive encapsulated powder quality. Food Bioprocess Technol. 12: 122146.

27. Gao H, Wen JJ, Hu JL, Nie QX, Chen HH, Nie SP, et al. 2019. Momordica charantia juice with Lactobacillus plantarum fermentation: Chemical composition, antioxidant properties and aroma profile. Food Biosci. 29: 62-72.

28. Wilkowska A, Ambroziak W, Czyżowska A, Adamiec J. 2016. Effect of microencapsulation by spray-drying and freeze-drying technique on the antioxidant properties of blueberry (Vaccinium myrtillus) juice polyphenolic compounds. Polish J. Food Nutr. Sci. 66: 11-16.

29. Avila-Reyes SV, Garcia-Suarez FJ, Jiménez MT, San MartínGonzalez MF, Bello-Perez LA. 2014. Protection of L. rhamnosus by spray-drying using two prebiotics colloids to enhance the viability. Carbohydr. Polym. 102: 423-430.

30. Ballesteros LF, Ramirez MJ, Orrego CE, Teixeira JA, Mussatto SI. 2017. Encapsulation of antioxidant phenolic compounds extracted from spent coffee grounds by freeze-drying and spraydrying using different coating materials. Food Chem. 237: 623631.

31. Çam M, Işıkı MD, Yüksel E, Alaşalvar H, Başyiğit B. 2018. Application of pressurized water extraction and spray drying techniques to produce soluble spearmint tea. J. Food Meas. Charact. 12: 1927-1934.

32. Mahdi AA, Mohammed JK, Al-Ansi W, Ghaleb AD, Al-Maqtari QA, Ma $M$, et al. 2020. Microencapsulation of Fingered citron extract with gum Arabic, modified starch, whey protein, and maltodextrin using spray drying. Int. J. Biol. Macromol. 152: 1125-1134.

33. Kalita D, Saikia S, Gautam G, Mukhopadhyay R, Mahanta CL. 2018. Characteristics of synbiotic spray dried powder of litchi juice with Lactobacillus plantarum and different carrier materials. LWT 87: 351-360.

34. Sosa N, Gerbino E, Golowczyc MA, Schebor C, Gómez-Zavaglia A, Tymczyszyn EE. 2016. Effect of galacto-oligosaccharides: maltodextrin matrices on the recovery of Lactobacillus plantarum after spray-drying. Front. Microbiol. 7: 584.

35. Both E, Gyorgy E, Kibedi-Szabo CZ, Tamas E, Abraham B, Miklossy I, et al. 2010. Acid and bile tolerance, adhesion to epithelial cells of probiotic microorganisms. UPB Buletin Stiintific, Series B: Chem. Mater. Sci. 72: 37-44.

36. Ding WK, Shah NP. 2007. Acid, bile, and heat tolerance of free and microencapsulated probiotic bacteria. J. Food Sci. 72: M446M450.

37. Andrade R, Santos E, Azoubel P, Ribeiro E. 2019. Increased survival of Lactobacillus rhamnosus ATCC 7469 in guava juices with simulated gastrointestinal conditions during refrigerated storage. Food Biosci. 32: 100470. 